\title{
Gestão Desportiva: análise das dissertações de Mestrado e teses de Doutoramento na Faculdade de Desporto da Universidade do Porto
}

\author{
José Pedro Sarmento \\ Maria José Carvalho \\ Ricardo Barreto Coelho \\ Daiane Miranda de Freitas
}

\author{
Faculdade de Desporto \\ Universidade do Porto \\ Portugal
}

\section{RESUMO}

Este estudo tem por objectivo caracterizar e compreender as linhas de investigação traçadas no Gabinete de Gestão Desportiva da Faculdade de Desporto da Universidade do Porto, desde a primeira (1998) à oitava edição do mestrado de Gestão Desportiva (2005).

Metodologicamente, os dados para investigação foram recolhidos pelos registos administrativos relativos aos alunos de mestrado e doutoramento, cujo tratamento passou pela análise descritiva de vários indicadores, designadamente: sexo, nacionalidade, orientadores, tempo total de obtenção do grau.

Recolhemos ainda o acervo de dissertações e teses relativas às edições supramencionadas e procedemos à sua diferenciação quanto às áreas científicas, metodologias e palavras-chave. Os resultados apontam que a área de investigação de Planeamento e Estratégia é predominante nas dissertações de mestrado (27\%), sendo as áreas de Direito do Desporto e Desenvolvimento Organizacional as que preenchem as áreas de investigação de doutoramento (50\%). A abordagem quantitativa e o estudo exploratório são as metodologias predominantes das dissertações de mestrado. Nos trabalhos de doutoramento a abordagem qualitativa e o estudo exploratório juntamente com a análise descritiva são mais representativos. Quanto ao tempo médio despendido até a apresentação e defesas públicas, os resultados apontam para 2 anos e 6 meses para os alunos de mestrado e 4 anos e 4 meses para os alunos de doutoramento.

Palavras-chave: gestão desportiva, áreas científicas, metodologias, investigação, dissertações e teses

\begin{abstract}
Sport Management: analysis of Master dissertations and Doctoral Theses from the Faculty of Sport, University of Oporto

The propose of this study is describe and understand the lines of research outlined in the office of Sport Management in Faculty of Sport at the University of Oporto, since the first (1998) to the eighth edition of the Masters of Sport Management (2005).

Methodologically, the data for research were collected by administrative records relating to the master's and doctoral students, whose treatment fell by descriptive analysis of several indicators, including: gender, nationality, guiding, total time for obtaining a degree. We collected even the body of dissertations and theses on the above issues and proceeded to its differentiation on the science, methodologies and keywords.

The results indicate that the area of research, Planning and Strategy is predominant in the master's dissertations (27\%), and the areas of the Sports Law and the Organizational Development fulfilling the areas of doctoral research (50\%). The quantitative approach and exploratory study are the predominant methodologies of the Masters dissertations. In doctoral work on the qualitative approach and exploratory study along with the descriptive analysis are more representative. On the average time spent by the public presentation and defense, the results point to 2 years and 6 months for the master's students and 4 years and 4 months for doctoral students.
\end{abstract}

Key-words: sport management, scientific areas, methodologies, research, dissertations and theses 


\section{INTRODUÇÃO}

A área da Gestão Desportiva teve ao longo dos anos um tratamento muito específico no currículo da Faculdade de Desporto da Universidade do Porto (FADEUP). Na década de oitenta a abordagem desta temática era realizada numa disciplina de características semestrais que decorria através da apresentação de temas por professores convidados.

A partir de 1995 mudou-se de estratégia e a disciplina à altura designada de Organização e Gestão do Desporto (OGD) foi atribuída a um professor da Faculdade, que lentamente iniciou um processo de afirmação da área dentro da Instituição. Este processo lento e difícil foi obtendo progressivamente pequenas e grandes vitórias numa fase inicial, e posteriormente entrou num período de impossibilidade de crescimento.

Numa primeira fase, conseguiu-se o aumento da carga horária através da utilização de uma hora prática, o que permitiu uma nova dinâmica. Mas, o grande momento deste processo de afirmação e crescimento deu-se em 1997 quando o Conselho Científico aprovou a proposta de criação de um Mestrado em Gestão Desportiva, que catapultou a Gestão Desportiva para um outro nível dentro do enquadramento das áreas científicas leccionadas na Faculdade.

O ano de 1998 tratou-se de um momento fulcral de afirmação e projecção da Gestão Desportiva como área disciplinar no currículo da Faculdade.

Já neste Século, teve lugar uma revisão curricular em que se colocou muita expectativa sobre a possibilidade de a Gestão vir a ganhar o estatuto de área opcional na licenciatura, mas tal não aconteceu. Enquanto isto, o Mestrado de Gestão Desportiva ia demonstrando grande vitalidade e procura, expressos na elevada percentagem de dissertações defendidas e num número estável de candidatos em cada ano.

Acompanhando este percurso na licenciatura e no mestrado foram-se desenvolvendo e finalizando diversas teses de doutoramento quer de estudantes portugueses como brasileiros.

Com o processo de Bolonha foi possível reformular em 2007 a estrutura do curso de Licenciatura e finalmente a Gestão Desportiva foi reconhecida como uma das mais importantes oportunidades de emprego na área das Ciências do Desporto, o que de forma coerente possibilitou a sua afirmação como uma das opções para a obtenção da Licenciatura em Ciências do Desporto em conjunto com o Treino Desportivo, Desporto e Populações Especiais e Exercício Físico e Saúde.

Assim a Faculdade de Desporto passa a oferecer no $1^{\circ}$ Ciclo de Estudos uma opção em Gestão Desportiva alicerçada em quatro cadeiras semestrais e mais uma optativa de Direito do Desporto.

Mantendo um $2^{\circ}$ Ciclo de estudos dedicado à Gestão Desportiva, na sequência do que foi o Mestrado com a mesma designação.

Este trabalho pretende de uma forma clara e objectiva traçar os principais contornos da produção de dissertações e teses orientadas pelo Gabinete de Gestão Desportiva da UPorto nos últimos dez anos, tentando esclarecer dados sobre quem as realizou, como as realizou e com a orientação de quem, refazendo assim, também, um pouco da história da Gestão Desportiva em Portugal.

Uma vez que a Gestão Desportiva é essencialmente uma plataforma de cruzamento de várias áreas científicas, que corresponde ao interesse fundamental em que cada documento se concentra, realizamos uma prospecção sobre a perspectiva de vários autores de reconhecida competência(1,11). Só depois de um estudo comparativo de diversas posições nos decidimos pela elaboração da grelha que agrupasse as áreas científicas abordadas pela amostra do nosso estudo. Assim, para Parkhouse (7) os aspectos fundamentais para um programa de Gestão do Desporto são: Domínio das actividades desportivas (behavioral dimensions in sport); Gestão e competências organizacionais em desporto (management and organizational skills in sport); Ética; Marketing; Comunicação; Finanças; Economia do desporto; Direito do desporto; Política desportiva; Experiência de terreno.

Danylchuck (2) enfatizava que os programas de Gestão do Desporto deveriam evoluir nos próximos anos em termos estratégicos, tendo em atenção quatro características fundamentais: Envolvimento com as faculdades de economia e gestão; Incrementar diversidade e especialização; Enfatizar os aspectos internacionais e globais; Melhorar a capacidade empreendedora. Devendo os currículos evidenciar as seguintes áreas do conhecimento: Marketing; 
Turismo; Recursos Humanos; Tecnologias da informação; Relações internacionais; Planeamento estratégico; Gestão de negócios.

Por outro lado, Pires e Sarmento(8) consideram que a Gestão Desportiva tem essência por ela própria, não defendendo directamente todas as áreas referenciadas pelos autores, mas essencialmente o contexto em que a gestão é exercida. Estes não crêem que nenhuma escola se possa arvorar em detentora de todas as soluções que respondam aos problemas gerenciais que o mundo do desporto está a levantar. Tanto o desporto como a sua gestão são processos em plena evolução. Por isso, o conceito de gestão do desporto é considerado como tendo em atenção seis questões fundamentais: (1) Polissemia; (2) Dimensão híbrida; (3) Tecnologia específica; (4) Contextualização; (5) Nível de intervenção; (6) Âmbito de intervenção.

Para identificar e compreender o percurso das teses e dissertações defendidas na Faculdade de Desporto, nos últimos dez anos, decidimos classificar segundo um conjunto de dados objectivos (sexo, nacionalidade, orientadores, tempo total de obtenção do grau e palavras-chave) e subjectivos (áreas científicas e metodologias utilizadas) referentes a cada trabalho académico, no sentido de refazer as opções fundamentais de investigação escolhidas.

\section{METODOLOGIA}

\section{Amostra}

Face ao objectivo deste estudo em caracterizar e compreender as linhas de investigação adoptadas pelos mestrados e doutoramentos no âmbito do Gabinete de Gestão Desportiva entre 1998 e 2008, estudamos 97 dissertações defendidas por alunos matriculados entre 1998 e 2006 no Mestrado em Gestão Desportiva, e 6 teses de doutoramento referentes aos alunos que as concluíram até junho de 2008.

\section{Procedimentos de recolha de dados}

Metodologicamente, os dados para investigação foram recolhidos pelos registos administrativos relativos aos alunos de mestrado e doutoramento, cujo tratamento passou pela análise descritiva de vários indicadores, designadamente: sexo, nacionalidade, orientadores, tempo total de obtenção do grau.

Recolhemos ainda o acervo de dissertações e teses relativas às edições supramencionadas e procedemos à sua diferenciação quanto às áreas científicas, metodologias e palavras-chave.

\section{Tratamento dos dados}

Com base nas reflexões anteriores e na necessidade de caracterização pelo confronto directo de todas as teses e dissertações da amostra, optamos por classificá-las seguindo as seguintes áreas científicas: Marketing/Patrocínio, Direito do Desporto, Desenvolvimento Organizacional, Planeamento e Estratégia, Qualidade, Gestão de Recursos Humanos, Instalações Desportivas, Eventos Desportivos e Ensaios.

A partir da análise dos procedimentos da metodologia caracterizados pela literatura especializada $(3,5,6,8)$ utilizamos para este estudo, em termos das metodologias, três princípios que melhor contextualizavam esta pesquisa: abordagem, técnicas de estudo e análise e os instrumentos. Assim sendo, convencionamos caracterizar as abordagens como: 1 - Qualitativas: as teses e dissertações que descrevem e produzem relatos de uma realidade; 2 - Quantitativas: os estudos que buscam medir e analisar as relações causais entre as diversas variáveis; 3 - Mistas: teses e dissertações que associam as abordagens qualitativas e quantitativas em simultâneo.

As técnicas de estudo e análise englobam várias possibilidades: 1 - estudos exploratórios; 2 - ensaios; 3 análise descritiva e 3 - análise documental.

Relativamente aos instrumentos de recolha de dados utilizados discriminamos: 1 - entrevistas; 2 - questionários; 3 - recolha bibliográfica; 4 - recolha de dados (directa ou documental); 4 - mista, quando na utilização de mais de um instrumento.

A apresentação de dados referentes ao género e nacionalidade dos alunos, foi necessária devido à importância da caracterização da amostra, principalmente por existir a presença de estudantes estrangeiros oriundos do Brasil, Angola e Argentina. O estudo sobre os orientadores teve por base sua relação com a FADEUP permitindo a sua caracterização em: interno e externo. Os orientadores internos são aqueles que fazem parte do corpo de docentes da Faculdade de Desporto da Universidade do Porto, e todos os restantes, doutorados ou especialistas, são externo. 
O tempo total de curso teve por base o tempo que decorreu entre a matrícula e a defesa das provas públicas, tendo relativamente este indicador a amostra sendo constituída por 69 alunos do mestrado e 6 do doutoramento.

Em relação às palavras-chave apresentadas nas dissertações apenas referenciamos as que foram mais de quatro vezes mencionadas. Enquanto que nas teses todas as palavras citadas foram consideradas.

\section{APRESENTAÇÃO E DISCUSSÃO DOS RESULTADOS}

Dada a juventude da área da Gestão Desportiva no âmbito do ensino universitário em Portugal não existem dados concretos sobre a importância relativa dos diversos trabalhos de investigação elaborados por autores portugueses nos últimos 35 anos neste contexto. O único dado conhecido da importância relativa da Gestão Desportiva no que concerne as investigações de revisão na globalidade dos trabalhos na área das Ciências do Desporto corresponde a uma tese de doutoramento de Adroaldo Gaya(4), de 1994, que atribui uma ocorrência em valores percentuais de apenas $1,2 \%$.

Decidimos para uma maior clareza de apresentação analisar de forma separada, mas comparativa, os resultados encontrados para as teses de doutoramento e dissertações de mestrado.

Há claramente uma superioridade do número de dissertações apresentadas pelo sexo masculino, o que também é evidente nos alunos que se inscreveram em cada um dos cursos de mestrado (Figura 1). E que, obviamente decorre da relação que existe da participação das mulheres nos cargos Dirigentes do sistema desportivo português. Este estudo mostra, no entanto, que há um crescente envolvimento das mulheres nas funções de direcção do desporto em Portugal, já que os valores globais se aproximam agora dos $30 \%$, contrariando outros valores de estudos anteriores de $19 \%$ (10).

Os alunos que concluíram o mestrado em Gestão Desportiva até 2008 foram maioritariamente do sexo masculino, representando $70 \%$ do total. As mulheres apenas igualaram os homens no $7^{\circ}$ mestrado ( 9 alunas), no qual ocuparam $50 \%$ das vagas.

O número de alunos do sexo masculino seguiu uma tendência decrescente. Enquanto isso, o sexo feminino teve uma tendência crescente. Podemos dizer que há

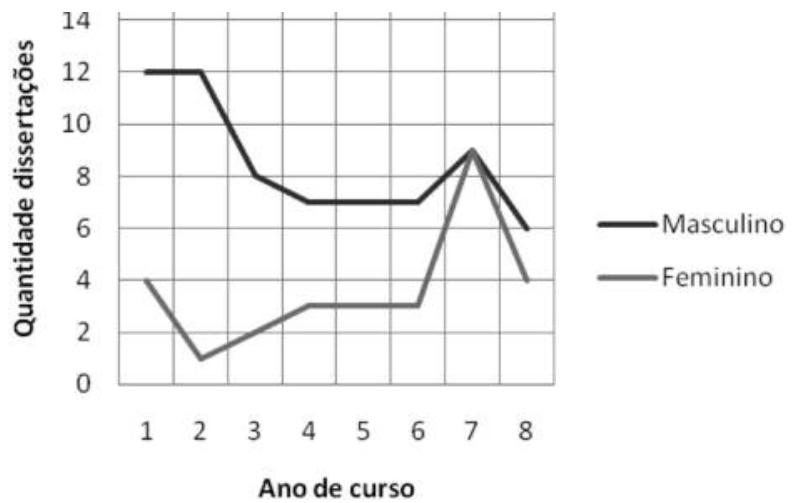

Figura 1. Relação do número de dissertações defendidas por sexo ao longo dos cursos de mestrado

uma tendência de aproximação, dado o aumento de participação das mulheres no contexto deste mestrado. Relativamente aos alunos do doutoramento, temos a participação apenas de uma mulher, o que corresponde a $17 \%$ (Figura 2). O que, comparativamente aos valores encontrados para o mestrado é inferior, mas continua a revelar uma tendência crescente da relação das mulheres com a Gestão Desportiva.

Figura 2. Percentagem de alunos de doutoramento por sexo

O mestrado em Gestão Desportiva na FADEUP apresentou a seguinte distribuição por nacionalidade (Figura 3): 87 alunos portugueses que concluíram o curso, incluindo os naturais e/ou residentes nas Regiões Autónomas dos Açores e Madeira, e 10 estrangeiros, compostos da seguinte forma: 7 Brasileiros, 2 Angolanos e 1 Argentino. 


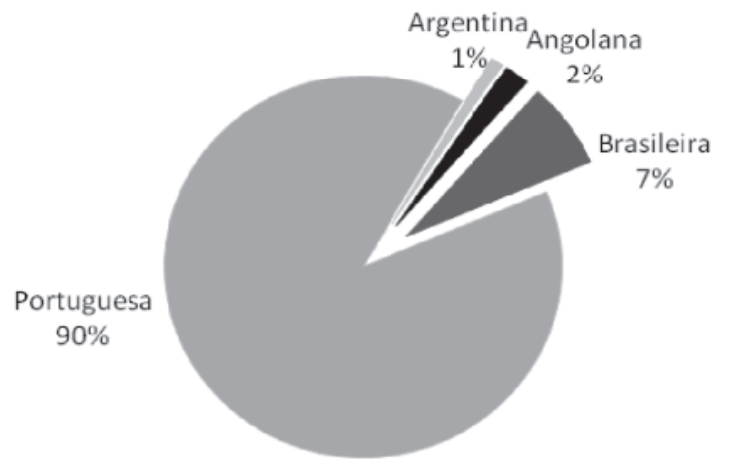

Figura 3. Percentagem de alunos de mestrado por nacionalidade

Relativamente às teses de doutoramento essas foram realizadas por 6 alunos, sendo 3 portugueses e 3 brasileiros (Figura 4).

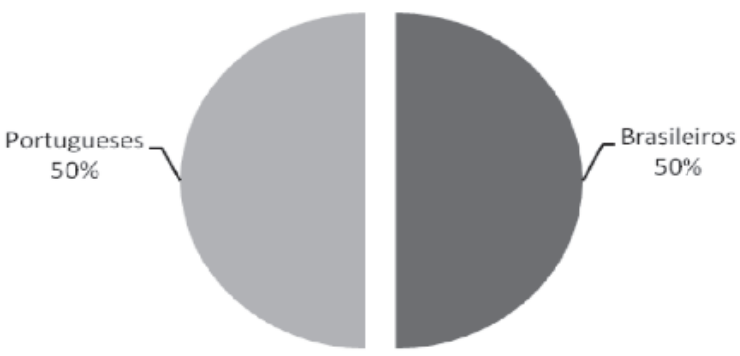

Figura 4. Percentagem de alunos de doutoramento por nacionalidade

Quer no mestrado como no doutoramento o aumento do número de alunos, principalmente brasileiros, tem vindo a aumentar progressivamente. Este facto deve-se a situação embrionária que a Gestão

Desportiva ainda possui no Brasil. O que não permite que os estudantes oriundos deste país possam desenvolver no seu local de residência os estudos nesta área, e se vejam obrigados viajar para outras universidades que já tenham esta formação mais desenvolvida.

Dos oito cursos de mestrado analisados apenas os de 2000 e 2003 não tiveram a defesa pública de dissertação por alunos brasileiros.

Dos dados recolhidos para análise do tempo médio despendido até a apresentação e defesa pública pelos alunos (Figura 5) podemos concluir que entre os valores médios para cada curso existe uma diferença de 8 meses (27 a 35) e que o valor médio foi de 30 meses. O que está de acordo com os valores impostos pela legislação.

O tempo médio despendido pelos alunos estrangeiros que concluíram o mestrado em Gestão Desportiva foi de 30 meses, o que é equivalente a média total.

O tempo médio gasto entre a entrega da dissertação e a defesa pública dos alunos foi de 2 meses e 24 dias, o que também está de acordo com o regulamento.

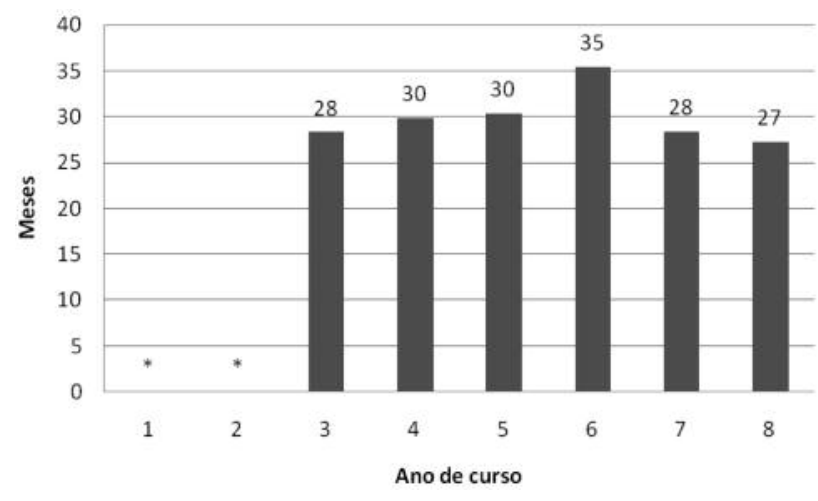

Figura 5. Tempo médio de conclusão do mestrado

Relativamente à elaboração das teses, a média total do tempo despendido foi de 52 meses, sendo que os estrangeiros realizaram em termos médios 49 meses e os portugueses em 55 meses. Este facto deve-se essencialmente à pressão que os estudantes brasileiros sentem não apenas para a obtenção do grau, mas também para reduzirem o tempo de estadia e de viagens à cidade do Porto. É de salientar ainda, que o tempo mínimo de execução da tese foi de 46 meses de um estudante brasileiro e o máximo foi de 59 meses de um português.

A área científica a qual corresponde à média mais alta para elaboração da dissertação do mestrado é de Qualidade com 33 meses e a que corresponde um tempo de execução mais baixo é de Desenvolvimento Organizacional, com valor médio de 28 meses (Figura 6). Relativamente às duas áreas científicas do doutoramento, o tempo médio despendido pelos alunos foi de 52 meses, respectivamente. 


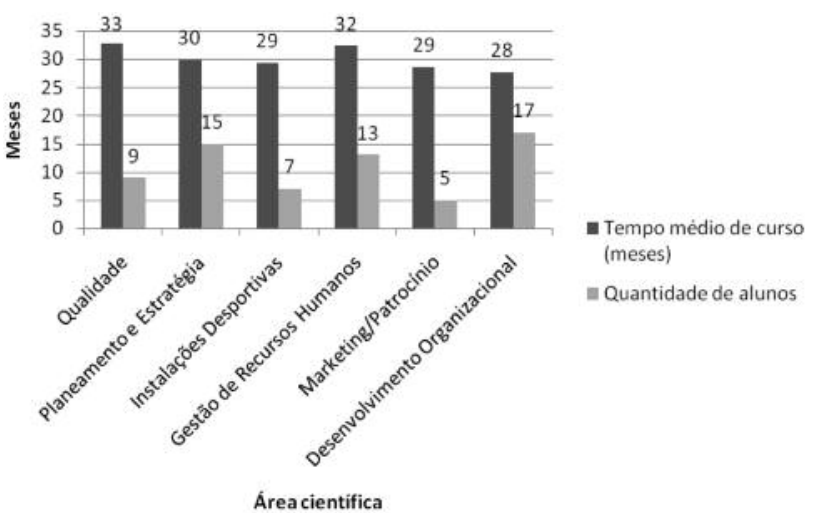

Figura 6. Duração média das dissertações do mestrado por área científica

$\mathrm{Na}$ orientação das dissertações do mestrado tiveram envolvidos 31 orientadores. $29 \%$ são docentes da FADE.UP e $71 \%$ são professores convidados de outras instituições, conforme apresentado na Figura 7. Pertencente à amostra de doutoramento temos 3 professores orientadores, sendo 1 interno com 4 orientações e 2 externos com 1 orientação cada.

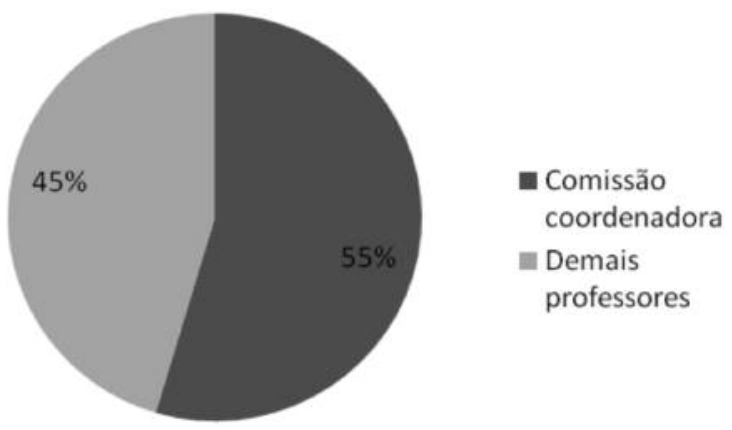

Figura 8. Percentagem de orientações das dissertações

90\% das orientações dos estrangeiros (Figura 9) foram realizadas por professores pertencentes à comissão coordenadora e $78 \%$ destas referem-se a apenas um dos professores.

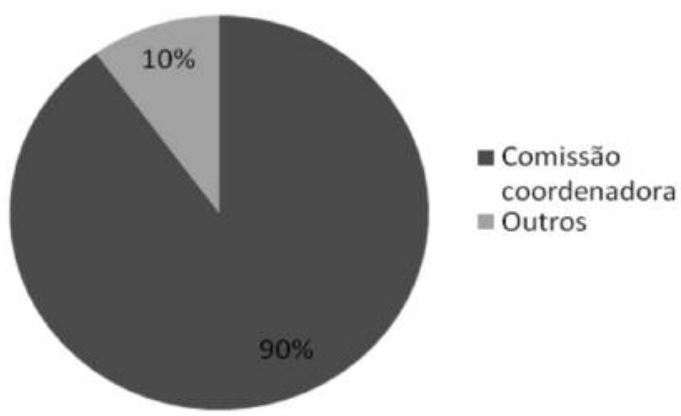

Figura 9. Percentagem das orientações de dissertações de estrangeiros

$51 \%$ dos Portugueses que concluíram o mestrado tiveram a orientação dos professores coordenadores do mestrado em Gestão Desportiva (Figura 10). A outra parte foi orientada por diversos professores, tanto internos como externos.

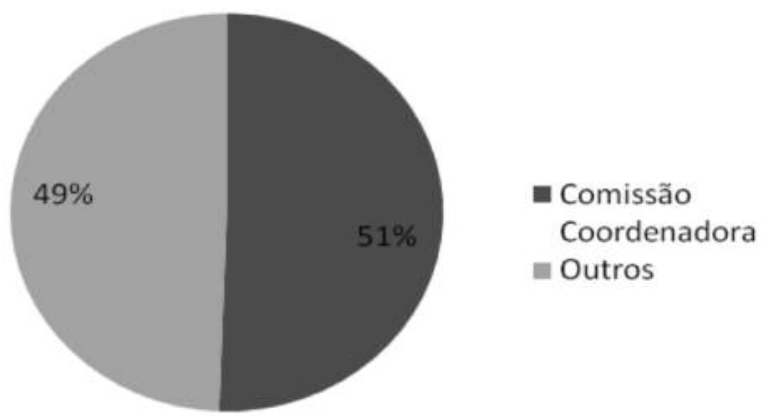

Figura 10. Percentagem das orientações de dissertações de Portugueses 
Na Figura 11 a seguir é possível verificar que a área de Desenvolvimento Organizacional apresentou 17 orientações realizadas por professores internos e apenas 1 externo. Mas, a área onde se realizaram mais dissertações, Planeamento e Estratégia, 16 alunos receberam orientação de professores internos e 10 externos. Apenas na área de Marketing/Patrocínio houve mais orientações de professores externos do que internos.

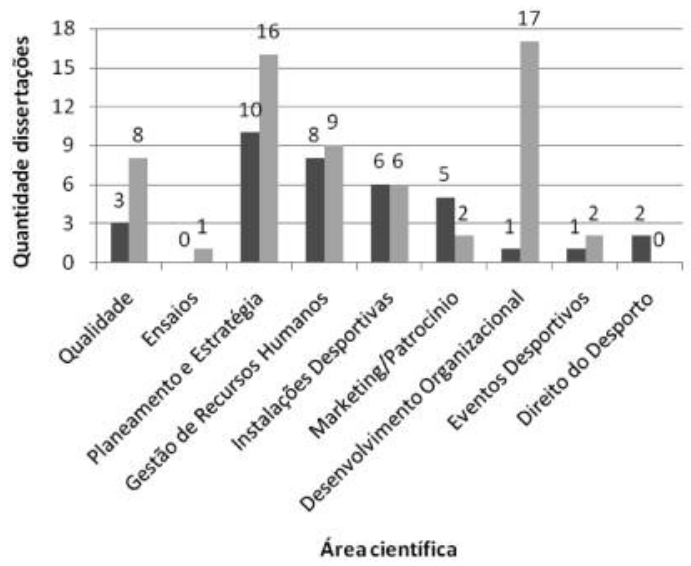

Figura 11. Relação da quantidade de orientadores internos e externos das dissertações por área de investigação

A distribuição das dissertações apresentadas pelas diversas áreas científicas não é regular ao longo dos anos. Aparecem sim, picos de interesse relativamente a cada área nos diversos cursos. Inicialmente vamos fazer a abordagem das áreas numa lógica global e somente depois analisaremos os diversos picos de interesse.

A área científica que apresentou maior percentagem de estudos no mestrado foi a de Planeamento e Estratégia, com $27 \%$ conforme identificado na Figura 12 , sendo a única área que esteve presente ao longo dos 8 cursos (Figura 13). Esta área recebeu mais atenção dos alunos que concluíram durante os dois primeiros anos de curso em Gestão Desportiva, com 6 alunos em cada ano. No $8^{\circ}$ curso teve a maior procura quando comparada com as outras áreas, correspondendo a 4 alunos.

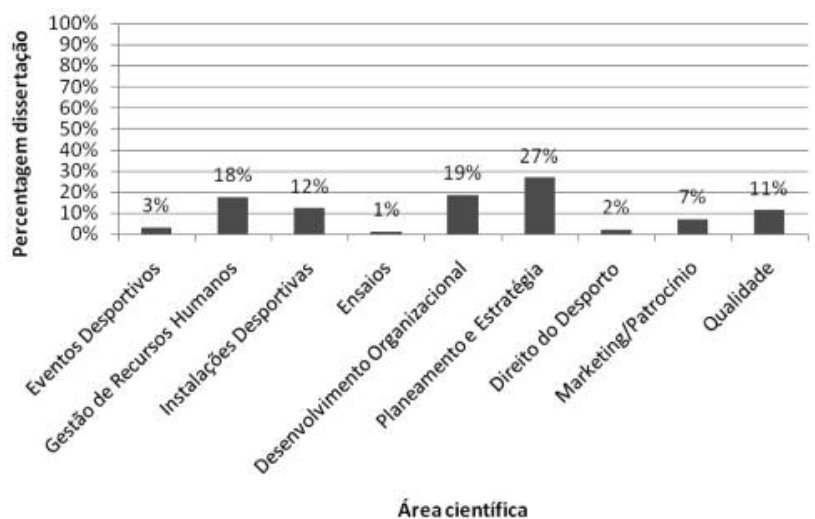

Figura 12. Percentagem das dissertações por área científica

A área de Desenvolvimento Organizacional foi a segunda mais investigada nos 8 cursos, correspondendo a 19\% (Figura 12). Esta área obteve maior número de alunos no $7^{\circ}$ curso, seguida neste caso pela área da Qualidade, com 5 alunos.

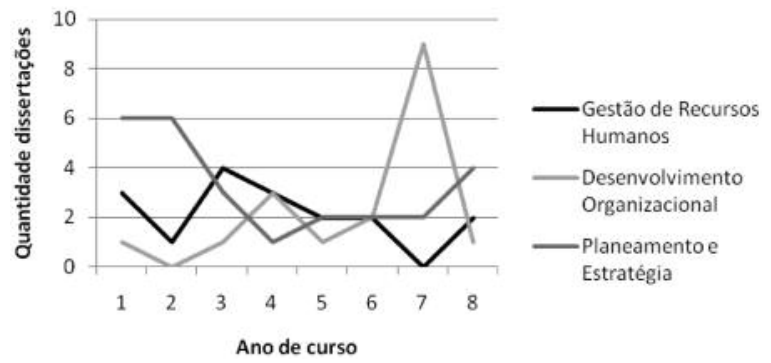

Figura 13. Quantidade de dissertações por área científica ao longo dos cursos

A área de Gestão de Recursos Humanos obteve no $3^{\circ}$ curso a sua maior procura com cerca de $40 \%$ dos alunos.

Relativamente às teses de doutoramento, as áreas em que elas foram englobadas são as de Desenvolvimento Organizacional e Direito do Desporto correspondendo exactamente $50 \%$ a cada uma delas.

Quanto ao processo metodológico destacamos que de entre as abordagens mais utilizadas pelos alunos surgem as Quantitativas, com $58 \%$ das dissertações (Figura 14). Esta abordagem foi a mais trabalhada nos 6 primeiros anos do curso. 
A abordagem Qualitativa teve um pico de concentração a partir do $7^{\circ}$ mestrado mantendo-se superior às outras abordagens nos 2 últimos anos. As dissertações que foram defendidas contendo a abordagem Qualitativa e Quantitativa ao mesmo tempo seguiu uma tendência mais ou menos constante ao longo dos 8 mestrados (Figura 14). Nas teses de doutoramento verificou-se $50 \%$ de utilização da metodologia qualitativa.

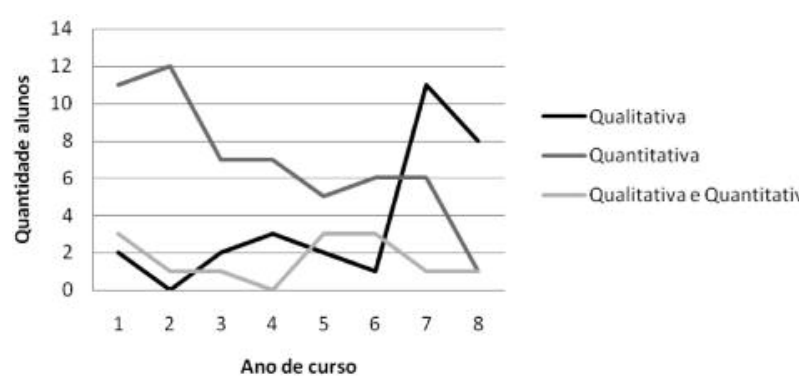

Figura 14. Relação das abordagens metodológicas nas dissertações de mestrado ao longo dos cursos

Dos dados recolhidos do mestrado podemos perceber que o estudo exploratório foi a técnica que se destacou na amostra, tendo aparecido muitas vezes associada a análise documental e análise descritiva (Figura 15). Nas 6 teses de doutoramento foi utilizada a técnica de estudo exploratório, de forma combinada ou isolada.

A análise descritiva, isoladamente, foi apenas utilizada em 2 dissertações, contudo, foi utilizada em simultâneo com o estudo exploratório, em mais dois trabalhos (Figura 15). A análise documental representou apenas $6 \%$ da amostra.

Quanto aos instrumentos de recolha de dados utilizados nas dissertações de mestrado verificamos que a operação mista representou $35 \%$. Enquanto o questionário, após uma estabilidade durante os 7 primeiros anos do mestrado, sofreu uma queda brusca no $8^{\circ}$ (Figura 16), a entrevista, que não apareceu no $4^{\circ}$ e $5^{\circ}$ anos consecutivos, teve um crescimento no $7^{\circ}$ e manteve-se no último ano de análise.

Relativamente às palavras-chave seleccionadas pelos autores das dissertações nota-se uma clara prevalência das designações da Qualidade, Organização/Estrutura e Desporto num primeiro grupo com mais de 20 citações, e depois um segundo grupo onde se evidenciam ainda as designações das Autarquias, Gestão, Formação, Actividade Física e Piscinas, todas elas com mais de 10 citações, conforme distribuição apresentada na Figura 17. A partir daqui forma-se um grupo de 16 designações, mas com muito menor representatividade, abaixo de 10 citações.

As palavras-chave citadas pelos alunos do doutoramento foram diversas e as mesmas se apresentaram uma única vez, com excepção da palavra Desporto que apareceu 2 vezes. São elas: Desporto, Parceria, Impactos, Estratégias, Extensão Universitária, Escola, Clube, Autarquia, Lazer, Tempo Livre, Direito do Desporto, Desporto Profissional, Clubes e Sociedades Desportivas, Ligas Profissionais, Competição Desportiva Profissional e Praticante desportivo.

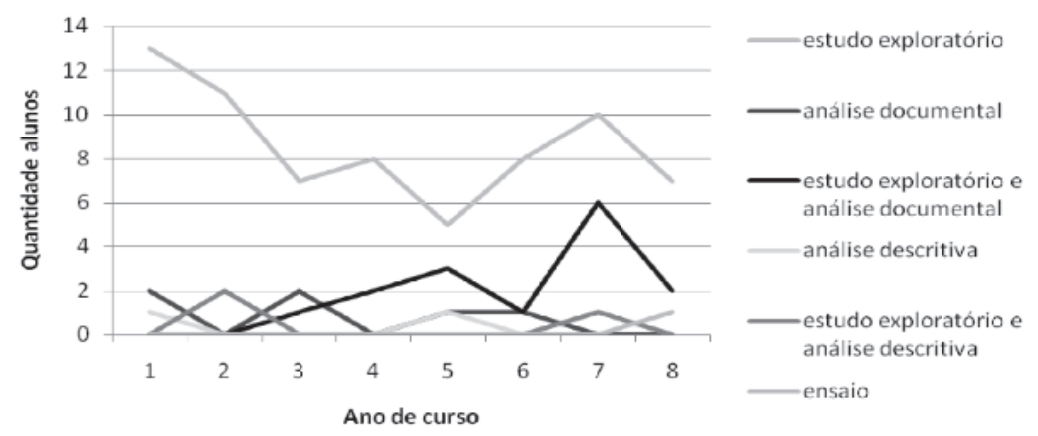

Figura 15. Relação das técnicas de análise e estudo nas dissertações de mestrado ao longo dos cursos 


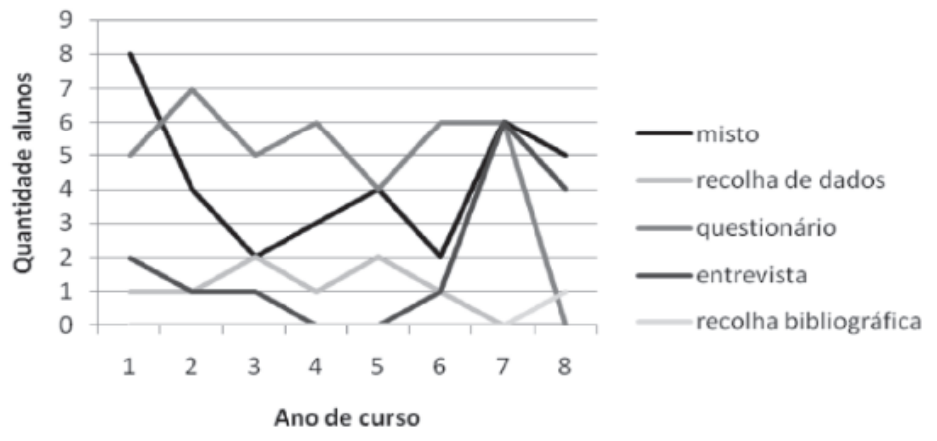

Figura 16. Relação dos instrumentos de recolha de dados nas dissertações de mestrado ao longo dos cursos

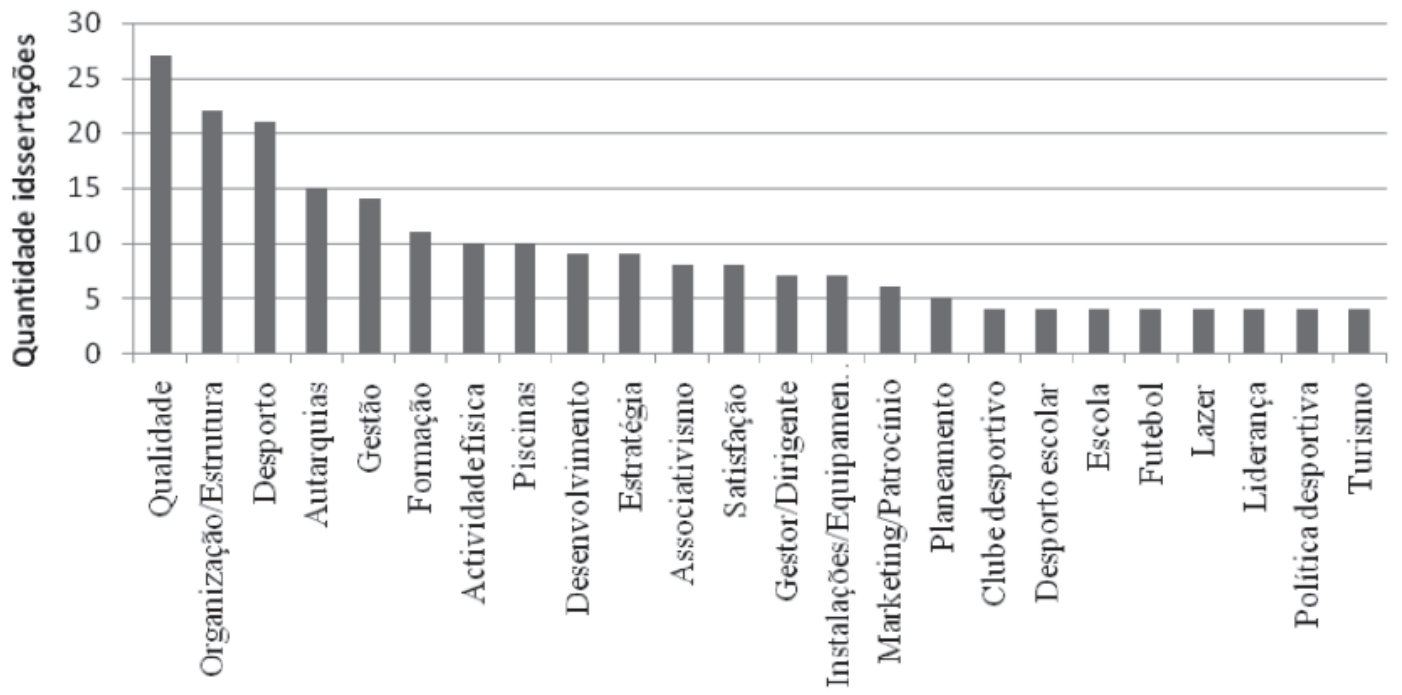

Palavras-chave

Figura 17. Relação do número de citações das palavras-chave nas dissertações de mestrado

\section{CONCLUSÕES}

Após este estudo podemos concluir que:

- Ainda prevalece o sexo masculino na investigação em Gestão Desportiva, mas sente-se uma clara evolução da participação da mulher.

- Apesar de participarem alunos de diversos países nestes programas de mestrado e doutoramento prevalecem maioritariamente os portugueses.

- O tempo de realização das teses e dissertações está dentro do previsto na legislação, havendo pequenas excepções.
- O maior número de orientações esteve a cargo dos membros da comissão coordenadora, assim como em termos globais prevaleceram os orientadores internos, havendo, no entanto um importante grupo de orientadores externos constituído por doutores e especialistas.

- As teses de doutoramento apenas foram agrupadas em duas áreas científicas, enquanto as dissertações de mestrado estão distribuídas pelas nove áreas científicas previamente formuladas. A área mais estudada foi a do Planeamento e Estratégia nas disserta- 
ções, enquanto no doutoramento a divisão foi equitativa entre Desenvolvimento Organizacional e Direito do Desporto.

- Em termos metodológicos sentiu-se ao longo dos anos alguma evolução principalmente relacionada com o aumento dos estudos qualitativos e a diminuição dos quantitativos e o recurso preferencial à utilização dos questionários e entrevistas como ferramentas metodológicas.

- Por fim, as três palavras-chave mais referenciadas correspondem à Qualidade, Organização/Estrutura e Desporto. Apenas a palavra Qualidade extravasa as expectativas iniciais, o que certamente corresponderá no futuro a uma das principais linhas de investigação na área da Gestão Desportiva.

\section{CORRESPONDÊNCIA}

\section{Daiane Miranda de Freitas}

Gabinete de Gestão Desportiva

Rua Dr. Plácido Costa, 91 - 4200-450 Porto, Portugal

E-mail: daianedefreitas@gmail.com

\section{REFERÊNCIAS}

1. Chelladurai P (2001). Managing organizations for sport $\mathcal{E}$ physical activity: a systems perspective. Scottsdale, Arizona: Holcomb hathaway, Publishers.

2. Danylchuck KE (1999). Sport Management as an Academic Discipline in the Next Millenium. Thessaloniki: Proceedings of the 7th Congress of the European Association for Sport Management. p. 16-9.

3. Denzin NK, Lincoln YS (2006). Introdução: a disciplina e a prática da pesquisa qualitativa. O planejamento da pesquisa qualitativa: teorias e abordagens. Porto Alegre: Artmed. p. 15-42.

4. Gaya ACA (1994). As Ciências do Desoprto nos Países de Língua Portuguesa. Uma Abordagem Epistemológica.

Porto: A. Gaya. Dissertação de Doutoramento apresentada à Faculdade de Ciências do Desporto e de Educação Física da Universidade do Porto.

5. Lakatos EM, Marconi MA (2005). Fundamentos de metodologia científica. 6 ed. São Paulo: Editora Atlas.

6. Lessard-Hébert M, Goyette G, Boutin G (2005). Investigação Qualitativa: Fundamentos e Práticas. 2a ed.: Éditions Agence d'ARC inc.

7. Parkhouse BL (1996). The Management of Sport: its Foundation and Application. St. Louis: Mosby Year Book.

8. Pires G, Sarmento JP (2001). Conceito de Gestão do Desporto. Novos desafios, diferentes soluções. Revista Portuguesa de Ciências do Desporto 1(1):88-103.

9. Quivy R, Campenhoudt Lv (2005). Manual de Investigação em Ciências Sociais. $4^{a}$ ed. Valente G, editor. Lisboa: Gradiva.

10. Sarmento JP, Pinto A, Oliveira AE (2006). O perfil organizacional e funcional do gestor desportivo em Portugal. Revista Brasileira de Educação Física e Esporte 20(Suplemento n.5).

11. Slack T (1997). Understanding Sport Organizations. The Application of Organization Theory. Champaign: Human Kinetics. 


\section{A criatividade como alavanca para uma melhor gestão desportiva}

\author{
Mafalda Moreira ${ }^{1}$ \\ Daiane Miranda de Freitas 2
}

\author{
${ }^{1}$ Faculdade de Engenharia \\ Universidade do Porto \\ Portugal \\ ${ }^{2}$ Faculdade de Desporto \\ Universidade do Porto \\ Portugal
}

\section{RESUMO}

O objectivo deste estudo é demonstrar que a criatividade amplia o espectro de soluções possíveis para as questões presentes nas actividades diárias de um Gestor Desportivo e das organizações desportivas.

Metodologicamente, os dados foram recolhidos da revisão bibliográfica dos principais autores sobre criatividade e pensamento sistémico. Num primeiro momento, o tratamento dos dados baseou-se na relação da " 5 a disciplina" de Peter Senge com os princípios, práticas e a essência de cada uma das cinco disciplinas em aprendizagem. Em seguida, no cruzamento das cinco disciplinas com factores de incentivo e barreira à criatividade dentro de uma abordagem sistémica e a partir de conceitos da criatividade organizacional e do pensamento sistémico. O resultado obtido mostrou-nos informações que poderão subsidiar o trabalho do Gestor Desportivo no sentido de promover o seu potencial criativo. Verifica-se, porém, a existência de diversas barreiras e incentivos à criatividade, as quais devem ser evitadas ou fomentadas, respectivamente, para se obter eficácia na gestão da organização. A criatividade actua como factor impulsionador da inovação na Gestão Desportiva, uma vez que surgem diversas soluções possíveis para as questões do dia-a-dia do Gestor e das organizações, constituindo-se uma alavanca para uma melhor Gestão.

Palavras-chave: criatividade, gestão desportiva, abordagem sistémica

\section{ABSTRACT \\ Creativity as leverage for better sports management}

The purpose of this study is to demonstrate that the creativity extends the specter of possible solutions for the questions in the daily activity of a Sporting Manager and the sporting organizations.

Methodologically, the data had been collected of the bibliographical revision of the main authors on creativity and systemic thought. At a first moment, the treatment of the data was based on the relation of " $5^{a}$ discipline" of Peter Senge with the principles, practical and the essence of each one of the five discipline in learning. After that, in the crossing of the five discipline with factors of incentive and barrier to the creativity inside of a systemic boarding and from concepts of the organizational creativity and the systemic thought.

The result obtained showed us informations that will be able to subsidize the work of the Sporting Manager in the direction to promote his potential creative. It is verified, however, the existence of diverse barriers and incentives to the creativity, which must be prevented or be fomented, respectively, to get effectiveness in the management of the organization. The creativity acts as factor booster of the innovation in the Sporting Management, a time that diverse possible solutions for the questions of day-by-day of the Manager and the organizations appear, consisting a handspike for one better Management.

Key-words: creativity, sports management, systemic approach 


\section{INTRODUÇÃO}

Para Pires e Sarmento(12) os desafios actuais encontrados na Gestão do Desporto implicam uma busca de diferentes soluções e oportunidades de intervenção que se multiplicam em função da criatividade das pessoas, das organizações e até da própria dinâmica social em que se encontram. Enquanto as organizações e os sistemas são capazes de acompanhar esta dinâmica tudo se desenrola de forma natural. No entanto, quando não existe essa capacidade surge a crise, tal como pode ser constatado em muitas organizações e sistema desportivo em Portugal. Nesta perspectiva, um clube, uma federação, ou qualquer outra organização deve ser vista como um sistema vivo em que os diversos recursos são geridos de forma a serem obtidos melhores resultados ao nível do planeamento, da liderança, da organização e do controlo. É evidente que um melhor funcionamento nestes domínios garante a eficácia e eficiência na obtenção de resultados desportivos.

A realização deste trabalho surge num momento em que se torna necessário repensar os modelos de Gestão Desportiva, reciclar mentalidades e encontrar uma forma de lidar com um mundo cada vez mais complexo, veloz e em contínua mutação.

Num mundo cada vez mais interligado, com os negócios mais complexos e dinâmicos, as empresas buscam na superação das deficiências de aprendizagem uma forma de reconhecer novas oportunidades e entender os perigos que bloqueiam seu desenvolvimento. Dentro desse contexto, Peter Senge, especialista em administração do MIT (Massachusetts Institute of Technology), apresenta sua revolucionária concepção das 'organizações de aprendizagem' - uma forma de administrar baseada em cinco disciplinas integradas pelo 'raciocínio sistémico' (a compreensão da realidade como um todo indivisível e auto-recorrente), que leva à compreensão dos perigos que ameaçam a sobrevivência da organização e a reconhecer novas oportunidades.

"Os seres humanos aprendem realmente quando há mudanças fundamentais na sua maneira de ver o mundo e alterações significativas de suas capacidades" (17, p.88).

A premissa de que o indivíduo tanto deve pensar localmente como globalmente, vai de encontro à teoria sistémica, que estuda as inter-relações de causa/efeito entre os vários elementos de um siste- ma - contempla o todo, os padrões e as partes. Esta abordagem estuda a complexidade das relações, tornando compreensível como as acções criam os problemas existentes num sistema ${ }^{(18)}$. É necessário ressaltar que na abordagem sistémica a totalidade do sistema é muito mais do que a soma das suas partes. Neste contexto, verifica-se a importância de adoptar modelos organizacionais dinâmicos e flexíveis, uma vez que manter a ligação a antigos paradigmas levará as organizações à estagnação e à perda de oportunidades. Neste sentido, o uso de técnicas de criatividade facilita a convivência na crescente complexidade organizacional que as novas tecnologias ajudaram a criar. Segundo Morais(10), a definição do conceito de Criatividade apresenta alguma controvérsia pela sua complexidade. Estamos perante um termo ambíguo que facilmente se confunde com termos como: génio, inteligência ou talento. Da imensidão de definições referentes ao conceito de criatividade, este trabalho baseia-se na definição de Tschimmel(19): "Capacidade cognitiva de um sistema vivo (indivíduo, grupo, organização) de produzir novas combinações (práticas, materiais, estéticas, semânticas), dar respostas inesperadas, úteis e satisfatórias, dirigidas a uma determinada comunidade.

É o resultado de um pensamento intencional, posto ao serviço da solução de problemas que não têm uma solução conhecida ou que admitem mais e melhores soluções que as já conhecidas."

A criatividade é vital para o sucesso das organizações e funciona como "o combustível que dá vida à inovação"(6), ou seja, é factor impulsionador da inovação. Neste sentido, o objectivo deste estudo é demonstrar que a criatividade amplia o espectro de soluções possíveis para as questões presentes no dia-a-dia de um Gestor Desportivo e das organizações desportivas. Isto significa que são necessárias cada vez mais estratégias originais para que o gestor possa ser realmente inovador e apresentar resultados competitivos.

\section{METODOLOGIA}

O procedimento metodológico adoptado para atender ao objectivo proposto baseia-se na revisão bibliográfica dos principais autores sobre criatividade e pensamento sistémico.

O tratamento dos dados foi realizado, num primeiro momento, com base na relação da " 5 a disciplina" de 
Peter Senge com os princípios, práticas e a essência de cada uma das cinco disciplinas em aprendizagem. Em seguida, baseou-se no cruzamento das cinco disciplinas de Peter Senge com factores de incentivo e barreira à criatividade dentro de uma abordagem sistémica de autores como Amabile(1), Hipple(7), Patterson(11), Rodrigo(15), Tschimmel(19), Williams e Yang(20) e conceitos de criatividade organizacional e do pensamento sistémico de autores como Bilhim(3),

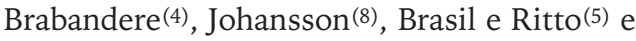

Ridderstråle(13).

Deste cruzamento, resultou a síntese de um conjunto de acções e características a fomentar e a evitar para atingir melhores resultados organizacionais. Buscou-se, a partir de então, exemplificar os dados obtidos do cruzamento dos conceitos com a realidade do sistema desportivo.

\section{RESULTADOS E DISCUSSÃO}

Através da exploração da abordagem sistémica do conceito de criatividade e de factores que fomentam o pensamento criativo pretende-se construir um discurso consistente orientado para o Gestor Desportivo e organizações desportivas.

A criatividade vista de uma perspectiva sistémica, ajuda o Gestor a identificar inter-relações entre diferentes elementos, em vez de observar cadeias de relações lineares. Desta forma, o Gestor do Desporto passa a compreender melhor a complexidade dinâmica das várias situações organizacionais e adquire ferramentas que lhe permitem lidar mais facilmente com essa complexidade.

Do ponto de vista sistémico, o leque de possíveis variáveis a observar pode ser estendido aos universos infinitamente grandes e infinitamente pequenos, uma vez que tudo são sistemas interligados e interdependentes, gerando efeitos de causalidade, muitas vezes difíceis de prever.

Peter Senge, autor de $A 5^{a}$ disciplina, criou este conceito em 1990 como resultado da associação do pensamento sistémico a um grupo de disciplinas que, convergindo e trabalhando em conjunto, visam melhorar a prestação das organizações. Falamos de:

1. Mestria Pessoal;

2. Modelos Mentais;

3. Visão Compartilhada;

4. Aprendizagem em Equipa;

5. Pensamento Sistémico.
A " 5 a disciplina" procura compreender como as acções de diversos sistemas originam futuras situações e problemas. Um dos seus objectivos assenta na compreensão da subtileza de determinadas interacções chave e de como estas influenciam comportamentos ao longo do tempo.

Para garantir a eficácia deste conceito no Sistema Desportivo é necessária uma mudança de mentalidade no seio das organizações, assim como a utilização do pensamento sistémico pelo Gestor Desportivo. De seguida serão descritas e referenciadas com a literatura as cinco disciplinas em aprendizagem que vêm convergindo para facilitar a inovação nas organizações que aprendem. Embora desenvolvidas separadamente, cada uma delas é fundamental para o sucesso das outras.

\section{Mestria Pessoal}

Trata-se de um ponto de vista criativo e não reactivo, sendo que através dos indivíduos que aprendem, as organizações aprendem.

Os Gestores Desportivos determinados a promover a Mestria Pessoal devem esclarecer continuamente o que é importante para si e aprender continuamente a visualizar com mais clareza a realidade do momento(18). As exigências aos quadros directivos no mundo do futebol hoje são, incomparavelmente, diferentes daquelas que colocaram nos últimos trinta anos. Mudanças estas que exigem dos Gestores Desportivos uma visão mais sistémica da realidade, envolvimento num conjunto de ideias, objectivos, processos e valores partilhados ${ }^{(9)}$.

\section{Modelos Mentais}

Os modelos mentais demonstram o entendimento individual de como o mundo funciona e, consequentemente, demonstram que as acções dos gestores estão por trás da sua visão do mundo. Consiste em reflectir, esclarecer continuamente e melhorar a imagem que cada um tem do mundo, a fim de verificar como moldar actos e decisões(18).

\section{Visão compartilhada}

Segundo Senge(18), o objectivo da visão compartilhada é estimular o engajamento do grupo em relação ao futuro que se procura criar e elaborar os princípios e as directrizes que permitirão que esse futuro 
seja alcançado. Esta disciplina é uma força nas organizações em aprendizagem, pois gera mais energia e aprendizagem.

Para Maçãs(9), o papel do Gestor Desportivo no futebol está no estabelecimento de uma ligação funcional prioritária entre a administração da organização e o cargo do treinador, bem como um conjunto de relações internas e externas à organização desportiva, neste caso, exigindo do mesmo uma visão compartilhada.

\section{Aprendizagem em equipa}

A disciplina de aprendizagem em equipa domina as práticas do diálogo e discussão como fundamentais para o seu desenvolvimento(14). Dentro das organizações desportivas, as equipas de sucesso desenvolvem um trabalho coordenado, onde cada membro tem consciência de que faz parte de uma equipa e age de modo a complementar as acções dos outros integrantes(2).

\section{Pensamento sistémico}

O pensamento sistémico reside na visão do todo, do detalhe, do padrão e das diversas inter-relações entre os elementos de um ou mais sistemas.

O Gestor Desportivo assume uma importância decisiva na gestão das organizações, tornando um dos activos estratégicos, com base no seu capital humano, alicerçado no seu conhecimento, qualificações e potencial inovador $(9)$.

Na tabela 1 encontram-se sintetizados os princípios, práticas e a essência de cada uma das cinco disciplinas em aprendizagem definidas anteriormente, assim como a sua relação com a " $5^{\text {a }}$ disciplina". Para clarificar o significado da palavra essência aqui apresentada, é assumido que se trata do estado experimentado naturalmente pelos indivíduos com alto nível de mestria em cada uma destas cinco disciplinas. Das cinco disciplinas de Peter Senge podemos retirar conclusões relativamente a incentivos e barreiras à criatividade. $\mathrm{O}$ cruzamento dos vários factores que fomentam e bloqueiam a criatividade organizacional com as cinco disciplinas em aprendizagem será aprofundado de seguida com exemplos do sistema desportivo e culmina na apresentação de uma tabela síntese (Tabela 2).

\section{Incentivos à criatividade}

Seguindo a questão já apontada e quase implícita de que o mundo está em constante mutação, é necessário cultivar a capacidade de mudar, quer ao nível pessoal, quer ao nível organizacional, para crescer e obter resultados positivos ${ }^{(11)}$.

$\mathrm{O}$ aumento de processos criativos constitui, por isso, um factor fundamental para aumentar a competitividade e inovação da organização desportiva.

A criatividade pode ser estimulada a partir do gosto pela aprendizagem(1). "O aprendizado não tem muito a ver com treinamento. $\mathrm{O}$ aprendizado ocorre no diaa-dia, ao longo do tempo" (17, p. 84). "Ele percebeu em mim não a minha vocação ou a possibilidade de me tornar um craque no voleibol, mas a persistência, a teimosia, a vontade de sempre voltar para um novo começo a cada derrota" (2, p.30). Estas palavras do técnico Bernardinho(2) referem-se as suas características pessoais percebidas pelo seu treinador de vôlei, sendo que, como atleta da época ou como técnico na actualidade, ele demonstrava e demonstra o gosto por aprender com os erros ou com as vitórias, em busca sempre da eficiência.

Para encorajar estilos de pensamento criativo na organização desportiva é necessário que cada elemento da organização tenha autorização e liberdade para o fazer, sendo que a presença de ciclos de feedback $(1,20)$ potencia o surgimento do pensamento criativo. Os vários momentos de feedback entre o Gestor Desportivo e todas as áreas, futebol negócio ou futebol jogo, com que este lida contribuem significativamente para a identificação de novas oportunidades expressas em serviços, produtos e estratégias inovadoras, além de garantir o melhor funcionamento sistémico da organização desportiva ${ }^{(9)}$.

A actividade auto-iniciada comporta sugestões de melhoramentos e desenvolvimentos organizacionais de forma livre, explorada e desenvolvida pelos vários membros da organização(14). É inevitável fazer uma análise inversa a este factor e, para isto, evidenciamos o sistema desportivo português que acaba por estagnar por falta não só de novos recursos humanos como pela desactualização daqueles que se perpetuam e multiplicam por vários lugares por anos a fio, alimentando-se das próprias organizações a que pertencem ${ }^{(12)}$.

Outro factor que incentiva à criatividade refere-se a estímulos diversos ${ }^{(14)}$, internos e externos à organi- 
Tabela 1. Essência, princípios, práticas e relação das disciplinas em aprendizagem com a " 5 a disciplina"

\begin{tabular}{|c|c|c|c|c|}
\hline $\begin{array}{l}\text { Disciplinas em } \\
\text { aprendizagem }\end{array}$ & Essências & Princípios & Práticas & Ligação com a " $5^{a}$ disciplina" \\
\hline Mestria Pessoal & $\begin{array}{l}\text { - Ser } \\
\text { - Gerar } \\
\text { - Ligação }\end{array}$ & $\begin{array}{l}\text { - Visão } \\
\text { - Tensão criativa vs } \\
\text { tensão emocional } \\
\text { - Subconsciente }\end{array}$ & $\begin{array}{l}\text { - Clarificar a visão } \\
\text { pessoal } \\
\text { - Manter a tensão } \\
\text { criativa (focar no } \\
\text { resultado, ver a } \\
\text { realidade actual) } \\
\text { - Fazer escolhas }\end{array}$ & $\begin{array}{l}\text { Integra razão e intuição, } \\
\text { compromisso com o todo e } \\
\text { uma visão do mundo mais } \\
\text { sistémica. }\end{array}$ \\
\hline Modelos Mentais & $\begin{array}{l}\text { - Defender a } \\
\text { verdade } \\
\text { - Abertura }\end{array}$ & $\begin{array}{l}\text { - Teoria adoptada vs } \\
\text { teoria em uso } \\
\text { - Equilibrar } \\
\text { questionário com } \\
\text { argumentação } \\
\end{array}$ & $\begin{array}{l}\text { - Distinguir } \\
\text { abstracções } \\
\text { baseadas em dados } \\
\text { (testar suposições, a } \\
\text { "coluna esquerda") }\end{array}$ & $\begin{array}{l}\text { Os modelos mentais expõem } \\
\text { suposições escondidas, } \\
\text { enquanto o pensamento } \\
\text { sistémico revela as causas de } \\
\text { problemas significativos. }\end{array}$ \\
\hline Visão Compartilhada & $\begin{array}{l}\text { - Propósito } \\
\text { comum } \\
\text { - Parceria }\end{array}$ & $\begin{array}{l}\text { - Visão partilhada } \\
\text { como holograma } \\
\text { - Compromisso vs } \\
\text { Submissão }\end{array}$ & $\begin{array}{l}\text { - Processo da visão } \\
\text { (partilhar visões } \\
\text { pessoais, ouvir os } \\
\text { outros, permitir } \\
\text { liberdade de escolha) } \\
\text { - Reconhecer a } \\
\text { realidade actual }\end{array}$ & $\begin{array}{l}\text { A visão cria a imagem do que } \\
\text { queremos. } 0 \text { pensamento } \\
\text { sistémico revela como } \\
\text { criámos a situação presente. } \\
\text { Adquire-se a percepção das } \\
\text { estruturas subjacentes que } \\
\text { limitam o crescimento. }\end{array}$ \\
\hline $\begin{array}{l}\text { Aprendizagem } \\
\text { em Equipa }\end{array}$ & $\begin{array}{l}\text { - Inteligência } \\
\text { colectiva } \\
\text { - Alinhamento }\end{array}$ & $\begin{array}{l}\text { - Integrar diálogo e } \\
\text { discussão } \\
\text { - Rotina defensiva }\end{array}$ & $\begin{array}{l}\text { - Suspender } \\
\text { suposições } \\
\text { - Agir como colegas } \\
\text { - Mostrar a própria } \\
\text { defesa } \\
\text { - Praticar }\end{array}$ & $\begin{array}{l}\text { O pensamento sistémico e as } \\
\text { suas ferramentas são } \\
\text { essenciais à aprendizagem } \\
\text { em equipa que envolve uma } \\
\text { luta com a complexidade. }\end{array}$ \\
\hline $\begin{array}{l}\text { Pensamento } \\
\text { Sistémico }\end{array}$ & $\begin{array}{l}\text { - Holismo } \\
\text { - Inter-ligação }\end{array}$ & $\begin{array}{l}\text { - Estrutura influencia } \\
\text { o comportamento } \\
\text { - Política de } \\
\text { resistência } \\
\text { - Vantagem }\end{array}$ & $\begin{array}{l}\text { - Arquétipos de } \\
\text { sistema } \\
\text { - Simulação }\end{array}$ & $\begin{array}{l}\text { A } 5^{a} \text { disciplina é a disciplina } \\
\text { que integra todas as } \\
\text { disciplinas e recorre, para } \\
\text { isso, à análise sistémica }\end{array}$ \\
\hline
\end{tabular}

Fonte: Senge ${ }^{(18)}$

zação, dos quais se tira algum tipo de vantagem para aplicar na organização. O Gestor Desportivo deve estar apto a equacionar a complexidade do futebol negócio e a complexidade do futebol jogo, tornandose criativo na gestão dos factores que influenciam directamente o rendimento em jogo (Lógica Interna do Jogo) e a organização desportiva em geral (Lógica Externa do Jogo) (9).
Além disso, promover situações em que os indivíduos possam criar novas soluções e desenvolver novas ideias ${ }^{(1)}$ estimula a criatividade. Ambientes como o do futebol, referido por $\operatorname{Maças}^{(9)}$, em que existem mudanças normativas, limitação de recursos humanos, a concorrência característica do meio e a necessidade de sobrevivência, justificam-se algumas das atitudes criativas do Gestor Desportivo para uma 
Tabela 2. Cruzamento dos vários factores que fomentam e bloqueiam a criatividade organizacional com as cinco disciplinas em aprendizagem de Peter Senge.

\begin{tabular}{|c|c|c|}
\hline $\begin{array}{l}\text { Disciplinas em } \\
\text { aprendizagem }\end{array}$ & Incentivos à criatividade organizacional & Barreiras à criatividade organizacional \\
\hline Mestria Pessoal & $\begin{array}{l}\text { Gosto pela aprendizagem } \\
\text { Liberdade pessoal para seguir os valores } \\
\text { organizacionais } \\
\text { Actividade autónoma auto-iniciada, } \\
\text { Observação e análise crítica do meio envolvente } \\
\text { (intra e extra organização) } \\
\text { Aceitação de ideias novas }\end{array}$ & $\begin{array}{l}\text { Crença de que a vantagem competitiva tem } \\
\text { bases sólidas } \\
\text { llusão de aprender com a experiência } \\
\text { llusão de ter o controlo } \\
\text { "Eu sou a minha posição" } \\
\text { Personalidade burocrática }\end{array}$ \\
\hline Modelos Mentais & $\begin{array}{l}\text { Comunicação entre os diferentes domínios e } \\
\text { subsistemas individuais da organização } \\
\text { Partilha de informação }\end{array}$ & $\begin{array}{l}\text { Personalidade burocrática } \\
\text { Pensamento conservador } \\
\text { Adesão rígida a regras } \\
\text { Inovação baseada no indíviduo médio }\end{array}$ \\
\hline Visão Compartilhada & $\begin{array}{l}\text { Não competição } \\
\text { Alinhamento de valores e objectivos } \\
\text { Compromisso }\end{array}$ & $\begin{array}{l}\text { "Eu sou a minha posição" } \\
\text { Pensamento conservador } \\
\text { Adesão rígida a regras }\end{array}$ \\
\hline $\begin{array}{l}\text { Aprendizagem em } \\
\text { Equipa }\end{array}$ & $\begin{array}{l}\text { Experimentação } \\
\text { Abertura a diferentes perspectivas } \\
\text { Feedback dos vários domínios } \\
\text { Adaptação de soluções } \\
\text { Comunicação constante }\end{array}$ & $\begin{array}{l}\text { Presença de estruturas de ranking } \\
\text { Fraco conhecimento das competências de } \\
\text { cada um } \\
0 \text { mito da equipa de gestão }\end{array}$ \\
\hline Pensamento Sistémico & $\begin{array}{l}\text { Sistema organizacional flexível } \\
\text { Exposição e análise de estímulos diversos para } \\
\text { fomentar soluções criativas } \\
\text { Observar ciclos de feedback }\end{array}$ & $\begin{array}{l}\text { A parábola do "sapo a ferver" } \\
\text { Fixação em eventos } \\
\text { Síndrome do "inimigo anda por aî" }\end{array}$ \\
\hline
\end{tabular}

Fontes: Amabile(1), Brasil e Ritto(5), Hipple(7), Patterson(11), Ridderstråle ${ }^{(13)}$, Senge ${ }^{(18)}$, Williams e Yang(20)

melhor dinâmica organizacional.

Evitar e desencorajar situações de competição implica em uma das formas de incentivo à criatividade, algo que Bernardinho, actual treinador da equipa de vôlei masculina do Brasil, fez muito bem quando se deparou com uma jogadora da sua equipa da época "solista que não pensa muito na orquestra" (p. 92). Segundo Bernardinho(2), "o que eu quis, e lutei muito para conseguir, foi fazer que ela dividisse sua luz, sua excelência técnica, com as demais jogadoras. E que desenvolvesse a consciência da interdependência que existe no voleibol".

$\mathrm{O}$ alinhamento como princípio que pode ser aplicado como alavanca ao processo criativo corresponde à compreensão e contribuição de toda a equipa para os objectivos da organização(14). Se os membros tiverem a sensação de que foram ouvidos, participando nas definições dos objectivos do seu trabalho e da sua organização, promoverão maior alinhamento, coesão com a organização e uns com os outros (3). "A disposição de uma equipe e o entendimento e a colaboração entre os jogadores na quadra podem ser mais decisivos que o brilho individual" (2, p. 46).

Cultivar o seguimento de valores organizacionais em substituição da aplicação de regras também favorece à criatividade para que o indivíduo mantenha a sua independência e opte por seguir esses mesmos valores(1). Uma das obrigações do Gestor Desportivo é provocar, desafiar, instigar, buscar nada menos que o máximo. Só isso faz crescer(2), pois a criatividade do 
grupo como resposta à solução dos diversos problemas é colocada em questão no momento em que se busca o melhor resultado.

A actividade não-oficial tem como objectivo melhorar a prestação da organização, na qual os membros deste sistema associam a sua vida diária à organização com uma visão crítica, encontrando facilmente novas soluções e alternativas que favoreçam todo o sistema(14). Serendipity ${ }^{1}$ corresponde aos acidentes agradáveis e proveitosos para a organização, embora os autores compreendam que o seu real significado esteja algo corrompido. É fundamental que o treinador de uma equipa monitore intensamente sua relação com os colaboradores em momentos de sucesso, e disponha de capacidade criativa para conscientizá-los de que ser bom é imprescindível, mas estar preparado sempre é indispensável(2).

O Gestor Desportivo deve fomentar o significado de "organização" como um sistema complexo, social, político e técnico, assim como deve anular os vários factores que inibem a criatividade(11). Os factores como a autonomia dada à equipa, a atenção para com os objectivos, a visão de cada um, a flexibilidade e a análise atenta, não só fomentam a criatividade como abrem portas para novos pontos de vista. Patterson(11) refere que a identificação de novas oportunidades e a abertura a novas perspectivas requer uma aprendizagem organizacional e individual que irá capacitar todo o sistema de ferramentas permitindo a integração das soluções inovadoras, resultantes do pensamento criativo, dos objectivos estratégicos e da realidade em que a organização se encontra inserida.

As consequências do aumento de processos criativos organizacionais orientados são a inovação e os resultados competitivos no mercado. A criatividade organizacional é a base para a criação da inovação e como tal, estes dois conceitos devem ser encarados de forma paralela e complementar.

Os sistemas organizacionais que reagem aos "porquês" com interesse e curiosidade e que respeitam o seu potencial criativo apresentam um maior potencial para evoluir, aprender e inovar(5).

\section{Barreiras à criatividade}

Se uma organização não fomenta a produção de prestações criativas de forma correcta, nem está atenta aos vários bloqueios existentes, não consegue assumir-se como uma organização em aprendizagem, uma vez que não evolui nem se adapta ao meio envolvente.

Para vencer as barreiras à criatividade, os gestores desportivos e as respectivas organizações devem focar a sua atenção em medidas que facilite a comunicação, o trabalho multidisciplinar, a auto-iniciativa, a liberdade pessoal e a não competitividade interna. Williams e Yang(20) defendem que os sistemas organizacionais tradicionais, rejeitam potenciais ideias pouco familiares e diferentes, quebrando qualquer fluxo de ideias e novos conceitos, pois fomentam um pensamento conservador, uma adesão rígida a regras e regulamentos, uma forte divisão de tarefas e uma presença de estruturas de ranking.

Na relação entre supervisores e colaboradores, um fraco conhecimento das competências de cada colaborador por parte do supervisor, leva frequentemente ao bloqueio de novas ideias por desconhecimento ${ }^{(18)}$. Uma característica fundamental do Gestor como forma de fomentar a criatividade da sua equipa, e não bloqueá-la, neste exemplo na função de treinador, é ter conhecimento de como o jogador pensa, como ele se sente, quais são as suas expectativas e seus limites(2).

Os autores Williams e Yang(20) defendem que indivíduos com uma personalidade burocrática se sentem ameaçados por conceitos de inovação e mudança, uma vez que o seu objectivo organizacional está centrado na segurança e manutenção do salário e posição que ocupam, seguindo as regras de forma excessiva.

Estas barreiras pessoais à implementação da criatividade organizacional, não são o único entrave(20). A hierarquia é também apresentada como factor de desencorajamento da criatividade, pela excessiva burocracia que implica, pela pouca importância que os gestores atribuem ao trabalho dos subordinados e pela ganância e insensibilidade com o que rodeia os gestores de carreira.

Ridderstråle(13) afirma que a "criação da novidade já não é opcional” para as organizações, mas mesmo assim ainda há obstáculos a enfrentar para que a inovação seja atingida. Um dos primeiros obstáculos assenta na própria definição do que é a inovação, que ainda se encontra associada aos limites da orga- 
nização em termos de produtos e recursos, quando esta apresenta um espectro mais alargado e ligado a processos criativos. O segundo é a crença de que a vantagem competitiva tem bases sólidas, intemporais e vitalícias. Para se manterem competitivas, as organizações não podem tomar como certa a sua posição no mercado e têm de estar em constante procura de novas fontes de vantagem competitiva. Por fim, o terceiro obstáculo foca na antiga concepção de inovação baseada no indivíduo médio, nas massas e em soluções genéricas, quando o que se passa nos dias de hoje é que os "extremos governam o mundo" e que soluções realmente diferentes, não focadas no que já existe, são as alavancas para o sucesso organizacional ${ }^{(13)}$.

De acordo com estas barreiras, é necessário criar estratégias e comportamentos que consigam desencadear resultados originais nas organizações desportivas, respondendo à permanente e veloz mudança em que a sociedade vive.

\section{CONCLUSÕES}

Ao analisar a literatura teórica sobre o pensamento sistémico e a criatividade no contexto organizacional deparamos com inúmeras informações que poderão subsidiar a actuação do Gestor Desportivo no sentido de promover o seu potencial criativo. Verifica-se, porém, a existência de diversas barreiras e incentivos à criatividade, as quais devem ser evitadas ou fomentadas, respectivamente, para se obter eficácia na gestão da organização.

O pensamento sistémico surge como antídoto para que o Gestor Desportivo lute contra o constante sentimento de impotência face à crescente complexidade com que se depara. O Gestor deve encarar as disciplinas que compõem esse pensamento como um só sistema, onde estas convergem criando uma onda de experiências e avanços na organização.

É preciso despertar para ver as inter-relações entre diferentes elementos, em vez de apenas observar cadeias lineares de causa/efeito, assim como analisar as estruturas como um todo ao invés de olhar para eventos isolados. A vantagem desta abordagem é que oferece ao Gestor Desportivo e, consequentemente, às organizações desportivas ferramentas que permitem compreender a complexidade dinâmica das situações sem se perder na complexidade do detalhe(18).
De modo geral, a criatividade amplia o espectro de soluções possíveis para as questões presentes no diaa-dia de um Gestor Desportivo e das organizações desportivas, constituindo, por conseguinte, uma alavanca para uma melhor Gestão Desportiva.

\section{NOTAS}

${ }^{1}$ A palavra serendipity teve a sua origem em 1557 , no livro de Michele Tramezzino intitulado "Os Três Príncipes de Serendip". Narra a história, que o rei Giaffer que governava a ilha de Serendip no extremo oriente, tinha três filhos que enviou fora da ilha de modo a completarem a sua formação. Durante a sua viajem e de forma sagaz, os três príncipes faziam constantes descobertas por acidente, o que contribuiu para a sua sabedoria como fututros reis de Serendip. O uso do termo serendipity foi inspirado pela história de Michele Tramezzino e os seus primeiros registos foram encontrados numa das cartas escritas por Horace Walpole (1717-97), filho do primeiro-ministro Robert Walpole ao rei George II (Florença). (online in http://www.espacoacademico.com.br/013/13mendes.htm, acedido em 02-03-08)

\section{CORRESPONDÊNCIA}

\section{Mafalda Vaz Pinto Moreira}

Rua Amadeu de Sousa Cardoso, 50, Ap703, $7^{\circ}$ andar Senhora da Hora, 4460-481, Matosinhos Portugal

E-mail: mafalda.moreira@gmail.com 


\section{REFERÊNCIAS}

1. Amabile T (1996). Creativity In Context. (1 $1^{\mathrm{a}}$ ed.). Boulder, CO: Westview Press.

2. Bernardinho (2006). Transformando suor em ouro. Rio de Janeiro: Sextante.

3. Bilhim JAF (2001). Teoria organizacional: estruturas e pessoas. Lisboa: Universidade Técnica de Lisboa - Instituto Superior de Ciências Sociais.

4. Brabandere L (1998). A gestão de ideias. Da criatividade à inovação. ( $1^{a}$ ed.). Lisboa: Instituto Piaget.

5. Brasil L, Ritto ACA (s.d.). Design, ambientes organizacionais e as suas relações. [Versão eletrónica]. Consult. 15 out 2007, disponível em

http://webmail.faac.unesp.br/ paula/Paula/ambientes.pdf

6. Dziersk M (2007). Design meet business: 'Business, this is... Design'. [Versão eletrónica]. Consult. 13 ago 2007, disponível em

http://www.fastcompany.com/resources/design/dziersk/de sign-meet-business-080307.html.

7. Hipple J (s.d.). Organizational Creativity and Innovation Today. [Versão eletrónica]. Consult. 15 out 2007, disponível em http://www.innovation-triz.com/papers/0503orgcreativity.doc.

8. Johansson F (2007). O efeito Medici. O que nos podem ensinar os elefantes e as epidemias acerca da inovação. Cruz Quebrada: Casa das Letras.

9. Maçãs V (2007). O Director Desportivo nas Organizações do Futebol em Portugal. Caracterização da Actividade dos Gestores de Desporto nos Clubes de Futebol profissional e não profissional. Revista Portuguesa de Gestão de Desporto 4(1 e 2): 74-93.

10. Morais MF (2001). Definição e avaliação da criatividade. ( $1^{\text {a }}$ ed.). Braga: Universidade do Minho.
11. Patterson C (s.d.). Individual and Organizational Creativity. [Versão eletrónica]. Consult. 15 out 2007, disponível em http://www.innovation.cc/news/innovationconference/patterson.pdf.

12. Pires G, Sarmento JP (2001). Conceito de Gestão do Desporto. Novos desafios, diferentes soluções. Revista Portuguesa de Ciências do Desporto 1(1): 88-103.

13. Ridderstråle, J., \& Nordström, K. A. (2006). Capitalismo Karaoke: Gestão para a Humanidade. ( $1^{\mathrm{a}}$ ed.). Lisboa: Público - Comunicação Social SA.

14. Robinson, A.G., \& Stern, S. (1998). Corporate Creativity: how Innovations and improvement actually happen. San Francisco: Berrett-Koehler Publishers.

15. Rodrigo, J., \& Tschimmel, K. (in press), «Sistemas Creativos: ¿Qué hace que tengamos más o menos ideas? La pasión por la creación de nuevos mundos visuales y el placer de mirar-los. Dos temas, un diálogo» in Pasión por Crear_Placer de Admirar_Necesidad de Transformar. Lä Coruña: Publicação Macuf.

16. Rosado, A., Costa, J., Mesquita, I., Rolla, M., \& Colaço, C. (2007). Representações dos Dirigentes Desportivos acerca da Formação dos Treinadores. Revista Portuguesa de Gestão de Desporto 4(1 e 2): 5-22.

17. Senge, P. (1998). As cinco disciplinas. HSM Management, julho-agosto, 82-88.

18. Senge, P. (1999). The fifth discipline. (2a ed.). Londres: Random House Business Books.

19. Tschimmel, K. (2003). O pensamento criativo em design. Reflexões acerca da formação do designer. [CD-Rom]. Lisboa: CPD.

20. Williams, W., \& Yang, L. T. (2004). Organizational Creativity. In R. Sternberg, (Eds.). Handbook of Creativity (pp.373-391). Cambridge: Cambridge University Press. 